\title{
A High Speed Networks Applications and Requirements
}

\author{
Younis S. Younis \\ Ministry of Education, Nineveh Education Directorate, Nineveh, Iraq \\ Email: fajirnet1@yahoo.com
}

(Received October 25, 2018; Accepted February 27, 2019; Available online March 01, 2020)

DOI: 10.33899/edusj.2020.164376, (C) 2020, College of Education for Pure Science, University of Mosul.

This is an open access article under the CC BY 4.0 license (http://creativecommons.org/licenses/by/4.0/).

\begin{abstract}
:
All areas of business and governmental organizations are currently dependent on information technology (IT) to meet business objectives of improving network service and maximizing limited resources.

In this paper the main problems that's represented by using the information network to transfer information such as text, image and video files, conversations or direct video lectures, periods of use that can cause bottlenecks and network downtime, in addition to the large number of users of the network and the causes of these problems.

The main objective of this paper is to find out what methods or means to overcome the problems that guide us in terms of optimal use of resources and components even if it is limited, and to determine which technologies are best depending on the typically, quality, importance and confidentiality of the information and the periods of arrival of the information to be transferred. The information is based on the type of networks adopted if they are localized on a given building or the scope of a city or a wide range to include a country or continent and so on.
\end{abstract}

Keywords: Information Systems, Hypermedia , Bandwidth explosion, medical imaging , Bitmapped image

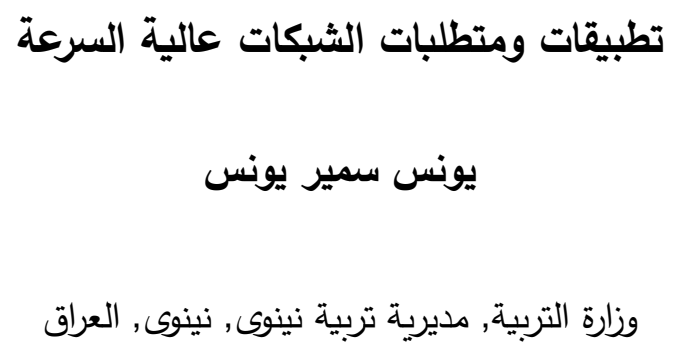




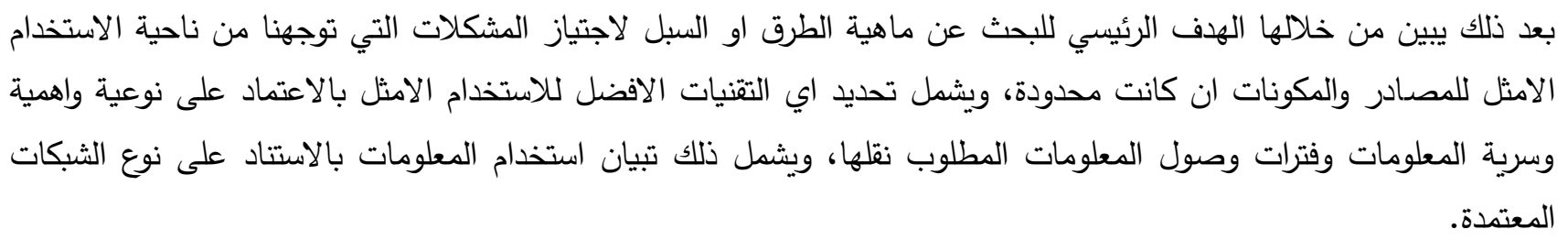
الكلمات المفتاحية :- نظم المعلومات ، الوسائط الفائقة ، تضخم عرض الحزمة ، التصوير الطبي ، الصورة النقطية

\section{Introduction}

Business and Government organizations depend on Information Systems (IS) and their supporting Information Technology (IT) to meet business objectives of improving services and maximizing limited resources. In the next few years, there will be an increasing exploitation of IS/IT, especially the use of telecommunications. New and more capable network technologies will be needed to respond to the increasing demand of using internet as global and networks as private[1][2].

there are Nine factors that influence the ways in which these new networking technologies might be deployed [2].

1- The increase and the change in using of IS/IT.

2- Improved cost/performance/ubiquiting of computing and telecom.

3- Different architectures (e.g., client-server, peer-peer).

4- Different and multiple media (graphics, image, video, etc).

5- Convergence of services (voice, data, video, etc).

6- Growth in distributed applications.

7- Reduction or avoidance of travel between locations.

8- Cooperative working within and between organizations.

9- the virtual office (e.g. home working, mobile users).

Figure (1) depicts a model that relates generic applications requiring high speed network to business functions and market sectors.

\begin{tabular}{|c|c|c|}
\hline $\begin{array}{l}\quad \text { Generic Applications } \\
\text { distributed case handing inter- } \\
\text { personal communications remote } \\
\text { delivery of expertise distributed } \\
\text { collaborative decision-making. } \\
\text { distributed learning/training } \\
\text { monitoring \& surveillance } \\
\text { telemarketing entertainment / } \\
\text { insure distribution multimedia } \\
\text { inter-personal messaging } \\
\text { multimedia information } \\
\text { assembly/ access distributed } \\
\text { collaborative design }\end{array}$ & $\begin{array}{l}\text { Manking / Finance / insurance } \\
\text { media / publishing / advertising / } \\
\text { culture retail / distribution } \\
\text { health care/public administration } \\
\text { manufacturing \& general industry } \\
\text { transport / travel / tourism } \\
\text { agriculture / utilities / education } \\
\text { building \& construction }\end{array}$ & $\begin{array}{l}\text { Business Functions } \\
\text {-operation / production } \\
\text { marketing / purchasing } \\
\text { transport / distribution } \\
\text { technical support/customs } \\
\text { services MIS / telecommunicates } \\
\text { administration/business planning } \\
\text { deign / research / human } \\
\text { resources / organization }\end{array}$ \\
\hline
\end{tabular}

Figure 1: A model that Relates generic applications requiring high speed networking [3] 


\section{Example of Future Applications}

Scenarios : Such as Distance learning, Remote consultation and Information services.

\subsection{Distance Learning}

This will enable the recipient to access remote multimedia databases and interactive instructions based on audio, image and video media. It will be applied to a broad range of subjects.

Teaching of surgery is a good example of the types of teaching, The students experience will be more varied if facilities, patients and medical expertise can be shared with university departments. Systems are already in place to supply two-way video and audio connections between the surgeon, tutors and students[4][5].

\subsection{Remote Consultation}

High cost and low availability of different types of consultants provide a strong case against travel. Use of rare and expensive specialists would be more effective if the gap between them, the clients and supporting facilities could be closed by suitable communications, namely, multimedia networking[6].

One example is: In the medical professions, some health authorities are unable to employ enough pathologists to cover specialized areas. Only a few consultants are study the pathology of the bones, and the rarer kinds of pathologists are found in universities, rather than hospitals[6].

\subsection{Information Services}

The high cost and short life expectancy of many types of books are posing some difficult access to libraries and information centers. This appeared to access information more rapidly with a suitable format (e.g. languages, textual, audio, colour) will take us electronic libraries are inevitable, therefore must using multimedia network[5][9].

\section{Bandwidth explosion}

The following trends in table (1) will collectively cause a dramatic increase in networking bandwidth $(\mathrm{BW})$ requirements over the next years.

To put the requirements into perspective, Figure (2) depicts will show each application area in terms of BW (bandwidth), L (latency), and typical segment lengths transmitted over the communications network.

One Example is: in image retrieval typically requires the transfer of picture from (500) Kbit/s to (20) Mbit/s, depending upon the resolution or complexity. Applications would typically require access times for retrieved images to be as fast as (0.5) Sec, or as long as (20) sec's. Thus, the network (BW) required to accomplish transaction is then identified by the diagonal lines which will be in the range $25 \mathrm{Kbit} / \mathrm{s}$ to $40 \mathrm{Mbit} / \mathrm{s}[5][7]$. 
Table (1) dramatic increase in networking bandwidth

\begin{tabular}{|c|c|c|}
\hline & types & Types of using \\
\hline 1 & $\begin{array}{l}\text { Increased using } \\
\text { of general } \\
\text { networking }\end{array}$ & $\begin{array}{l}\text { - many people will use IS/IT and per head; } \\
\text { - Increase use of file servers for security, integrity, etc. especially } \\
\text { for graphics, image and video. } \\
\text { - for remote access over increasing distances. } \\
\text { - mobile users requiring access from multiple locations. } \\
\text { - distributed processing (especially distributed databases) and client- } \\
\text { server architectures. } \\
\text { - Network for end systems managements, including software } \\
\text { distribution. } \\
\text { - On-line, back-up and recovery. }\end{array}$ \\
\hline 2 & $\begin{array}{l}\text { Need for } \\
\text { improved } \\
\text { performance }\end{array}$ & $\begin{array}{l}\text { - in computing power at all levels (especially in PCs). } \\
\text { - more powerful WS and application servers optimized for faster } \\
\text { inter interconnection. } \\
\text { - disk-less PCs-requiring program and file delivery in real time. } \\
\text { - client-server and client-client applications in real-time. }\end{array}$ \\
\hline 3 & $\begin{array}{l}\text { New } \\
\text { technological } \\
\text { developments }\end{array}$ & $\begin{array}{l}\text { - voice and non-voice services over the network. } \\
\text { - CAD / CAM. } \\
\text { - image including document capture and distribution (e.g., medical } \\
\text { imaging). } \\
\text { - video, broadcast TV, training services, video conferencing. } \\
\text { - Multimedia and hypermedia. }\end{array}$ \\
\hline
\end{tabular}

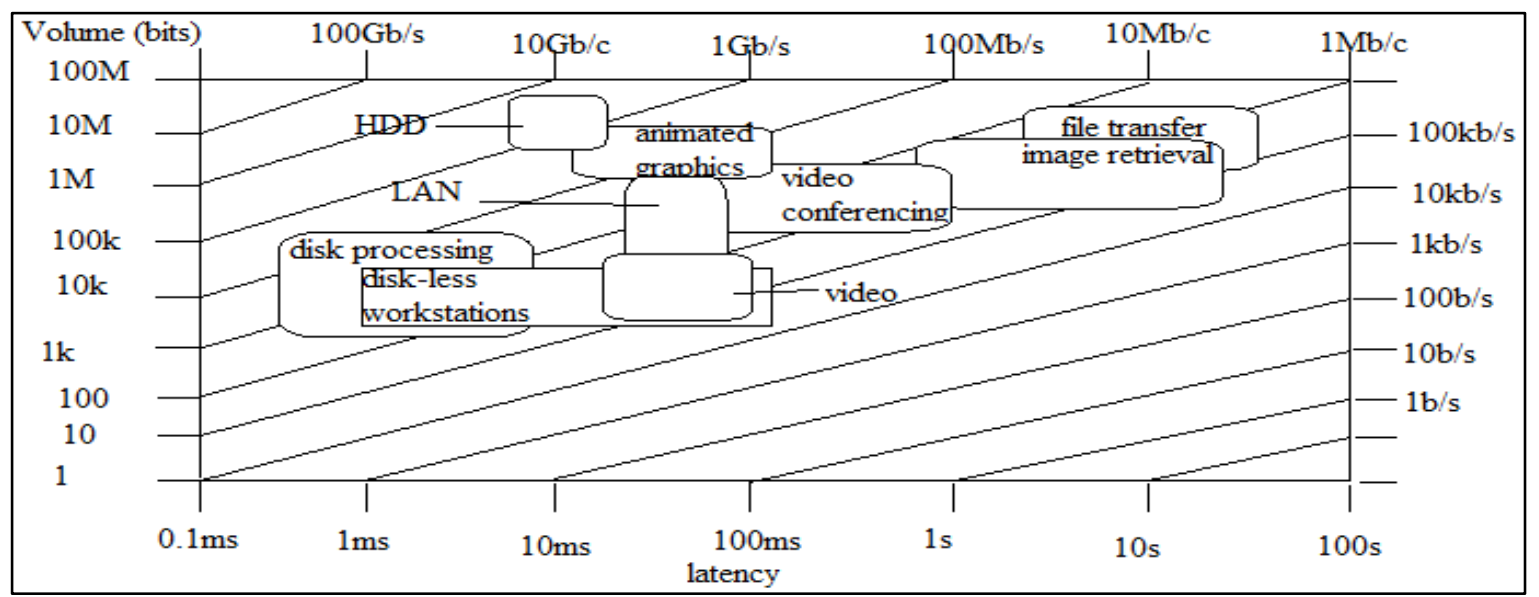

Figure 2: Volume, Latency \& Bandwidth Requirements[6]

\section{Increase Usage of Existing Applications}

People are making more use of IS/IT in the work by putting high requirement on the network between systems. This will have major short-term implication for managing traffic.

traffic sizing and forecasting will become more important. Use of traffic analysis tools will become prerequisite in monitoring quality of service statistics and the growth in traffic BW. There will be an increased requirement for effective network management and a higher level of interworking between dissimilar systems[6][10]. 


\section{File Transfer}

This covers the transfer of large blocks of information, typically:-

a- download files from host computers to LAN servers.

b- word processing documents and spread sheets.

c- engineering drawings from a mainframe computer to WS.

File transfer is growing steadily but only complex engineering drawings are presently taxing existing network technologies. Documents and spread sheets are expected to remain small (40-60KB) but will be transferred more frequently by E-mail in the future[4][7][9].

Thus, file transfer traffic will comprise large blocks of asynchronous data, with no serious demands on delivery time. Local file transfer can be accomplished with most generally available LAN technologies, however careful design may be needed to guarantee access and delivery times if a high level of client-client and inter-server traffic exists[4].

\section{Image-Based Applications}

These applications are appearing in a number of market sectors, including:

a- health (medical imaging).

b- finance and the utilities (capturing and storing paper records).

c- research and engineering (CAD).

These applications will find general use as costs fall-providing.

Virtual reality is the ultimate application of animated images/graphics, although many of the business use this technology have yet to be defined[6].

Thus, the information content of RD images will place significant demands on network BW. For example, 625-line broadcast TV contains $3 \mathrm{Mbit} / \mathrm{s}$ per frame, and many CAD and medical images contain at least 10 Mbit of information [1][7].

Image transmission would be performed synchronously effectively as a large file transfer. however the image traffic would need careful management particularly could be using by the FDDI. Using of ATM may have distinct advantages in providing high BW and efficient LAN interconnection mechanisms [9][10][11]. Switched Multimegabit Data Service (SMDS) could provide an ideal service within the metropolitan area as this operates at bit rates in the range 2-140 Mbit/s[4][10].

\section{Video Applications}

It includes:

- video telephony

- video conferencing

- Training

- Bulletins

- security surveillance

- support of broadcast TV

- in -store catalogue shopping (precursor to multimedia).

Video telephone will eventually provide a service to the office and the home [13].

Video conferencing is already a common place within medium/ large utilization. Fig. (3) depicts an analysis of the use of video conferencing, which is based on actual purchases made during $29 \mathrm{H}$. High quality video supporting broadcast TV and training are supplied today via off-air receivers and VCRs. Cable service is expected to become more suitable for the future of high quality video; this is due to congested radio spectrum and the wide BW needed to accommodate HD TV BISDN that will carry distributive video services for commercial, education, and entertainment applications in the future [8][10]. 
Thus, video conferencing is generally accomplished today (inter-site, inter-organization) at bit rates in the range 64 up to $384 \mathrm{k}$ bits. This could be supported easily and economically by N-ISDN [12].

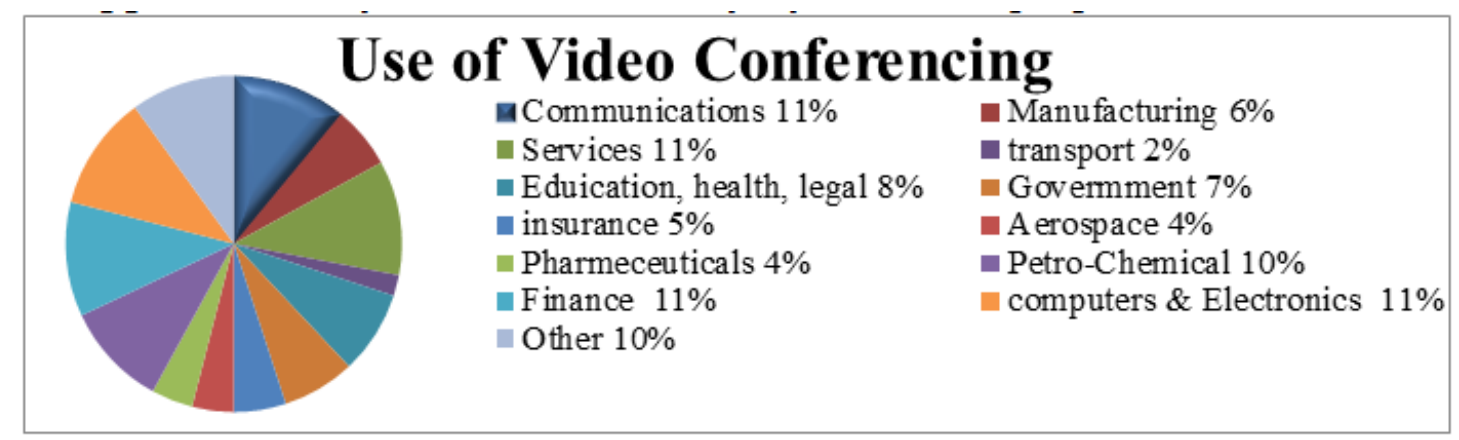

Figure 3: Use of Video conferencing by Market Sector[10]

Digital transmission of high quality (uncompressed) video is extremely demanding on BW, for example, it would require between $70 \mathrm{Mbit} / \mathrm{s}$ and $140 \mathrm{Mbit} / \mathrm{s}$, depending on whether it was domestic or studio quality [1][8]. Digital uncompressed HDTV will require (10) times from this BW. Future developments in data compression will ease these requirements. Today, it is possible to transfer quality compressed video for presentation in small window at a rate of $1.5 \mathrm{Mbit} / \mathrm{s}$ [8].

\section{Voice/Audio Applications}

Interactive voice communications will soon be based on $64 \mathrm{Kbit} / \mathrm{s}$ pulse code modulation (PCM), with Adaptive PCM (ADPCM) techniques following to compress its BW to 32, 16 or even $8 \mathrm{Kbit} / \mathrm{s}$ (silence not encoded). $64 \mathrm{Kbit} / \mathrm{s}$ transmission will be used for the majority of interactive voice communications in the local environment (which is mostly cabled, and where channel BW not an issue) and ADPCM voice transmission will be used for long distance transmission and for wireless WANs (where channel BW is limited)[9][14].

Real time voice communications will have strict requirements on delay variability, especially when compressed [14].

Voice messaging applications will not have the same BW or delay variability constraints and will not require high channel integrity[5][14].

Thus, voice messaging can easily be supported by all types of local and wide area network technologies [10].

\section{Multimedia/ Hypermedia Applications}

Multimedia provide more user-oriented computer systems, targeted at increasing the effectiveness of IT as a vehicle for inter-personal communications and cooperative working[1][3].

Multimedia include 1) education, 2) training, 3) in-store catalogue shopping, 4) interactive job assistance in technical environment. Figure (4) shows the current attitude on the benefits and the barrier for multimedia applications [3][6]. 


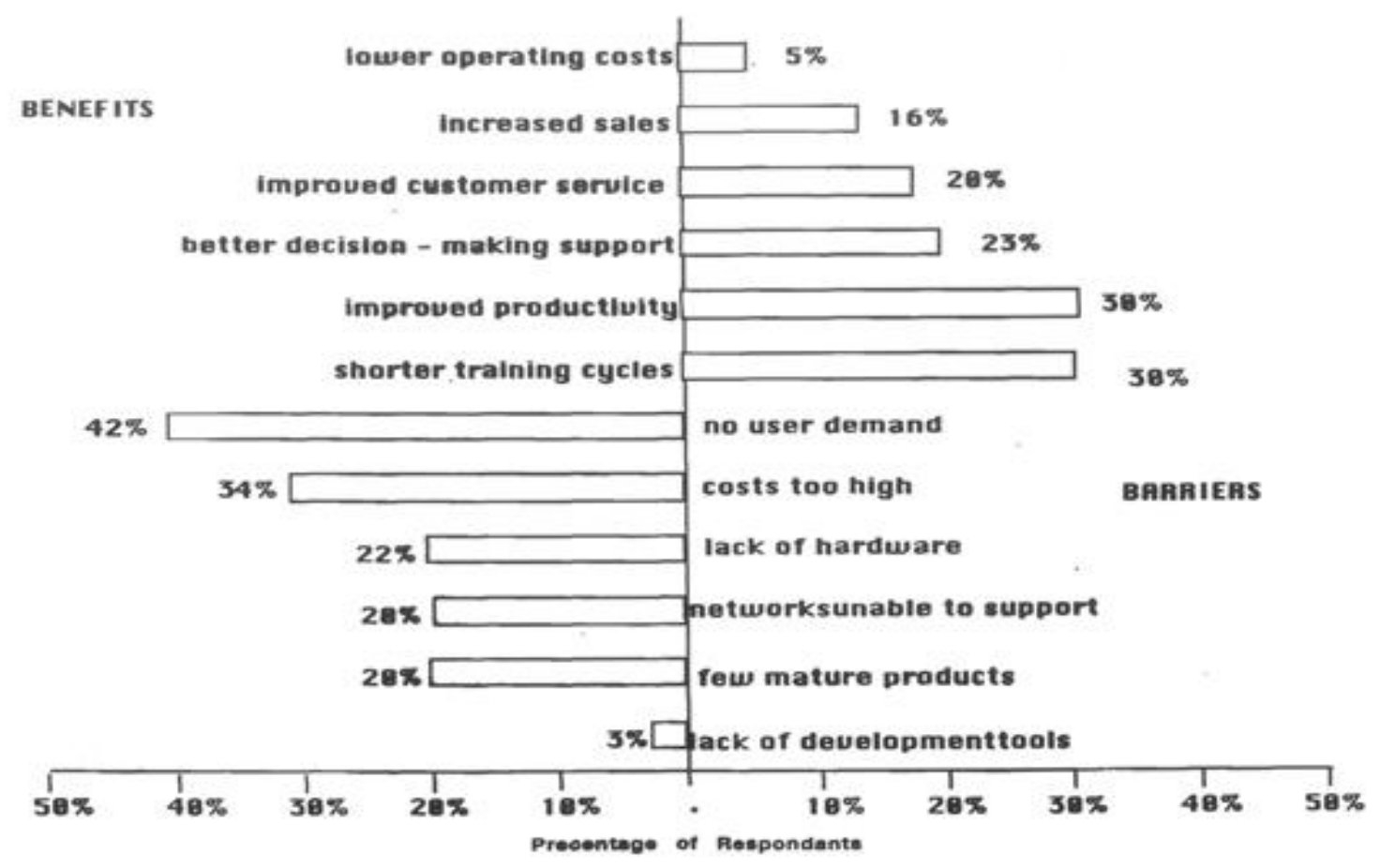

Figure 4: Benefits \& Barriers of Multimedia Applications

Hypermedia refers to a set of technologies that deals with a new way of organizing and providing associations between different elements of multimedia information. So Hypermedia will lead to very high levels of user interaction and consequently very low latency! high BW within the communications channel [1][6][9].

Thus, the raw information content associated with high quality communication services are typically as follows in table(2).

Table (2) uncompressed information

\begin{tabular}{|l|l|}
\hline voice & $64 \mathrm{Kbit} / \mathrm{s}$ \\
\hline music & $700 \mathrm{Kbit} / \mathrm{s}$ \\
\hline Bit-mapped image & $384 \mathrm{Kbit} / \mathrm{s}$ \\
\hline video & $70 \mathrm{Mbit} / \mathrm{s}$ \\
\hline
\end{tabular}

Compression techniques are available to reduce these high levels of information, with video being transferred at bit rates in the range $64 \mathrm{Kbit} / \mathrm{s}$ to $4 \mathrm{Mbit} / \mathrm{s}$ having acceptable quality for the applications listed above. Real time services (compressed and uncompressed) will need careful control over delay variability within packet switched network (PSN).

In table(3) lists the media profiles for the different multimedia applications and their requirements upon the communications network [1][11].

Unlike the majority of existing networked applications which support single media and homogenous traffic, multimedia networks must carry heterogeneous traffic (i.e, both continuous and burst, narrow band, low and high quality of service) [6][7]. 
Table (3) lists the media profiles

\begin{tabular}{|c|c|c|c|c|c|c|c|c|c|}
\hline \multirow[b]{2}{*}{ Application } & \multicolumn{6}{|c|}{ Media profile } & \multicolumn{3}{|c|}{$\begin{array}{l}\text { Network } \\
\text { equirements }\end{array}$} \\
\hline & $\cdot \frac{8}{0}$ & صేّ & $\stackrel{\vec{e}}{e}$ & $\begin{array}{l}\mathscr{\infty} \\
\stackrel{8}{\Xi}\end{array}$ & $\stackrel{?}{\stackrel{0}{\overparen{\tau}}}$ & $\frac{8}{\frac{0}{2}}$ & 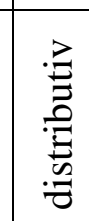 & 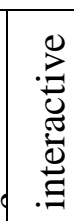 & 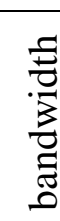 \\
\hline banking & $*$ & $*$ & $*$ & $*$ & & & $\mathrm{H}$ & $\mathrm{M}$ & M \\
\hline insurance & $*$ & $*$ & $*$ & $*$ & & & $\mathrm{H}$ & $\mathrm{M}$ & M \\
\hline medical imaging & & $*$ & $*$ & $*$ & & & $\mathrm{~L}$ & $\mathrm{M}$ & $\mathrm{H}$ \\
\hline real estate & & $*$ & $*$ & $*$ & $*$ & $*$ & $\mathrm{H}$ & $\mathrm{H}$ & M \\
\hline education & $*$ & $*$ & $*$ & $*$ & $*$ & $*$ & M & $\mathrm{M}$ & M \\
\hline distance learning & $*$ & $*$ & $*$ & $*$ & $*$ & $*$ & $\mathrm{H}$ & $\mathrm{H}$ & $\mathrm{H}$ \\
\hline advertising & & & $*$ & $*$ & $*$ & $*$ & $\mathrm{H}$ & $\mathrm{H}$ & $\mathrm{H}$ \\
\hline publishing & & & & $*$ & $*$ & $*$ & $\mathrm{H}$ & $\mathrm{H}$ & $\mathrm{H}$ \\
\hline travel agency & & & & $*$ & $*$ & $*$ & $\mathrm{H}$ & $\mathrm{H}$ & M \\
\hline cooperative working & $*$ & $*$ & $*$ & $*$ & $*$ & $*$ & $\mathrm{~L}$ & $\mathrm{H}$ & $\mathrm{H}$ \\
\hline library & & & & $*$ & $*$ & $*$ & $\mathrm{H}$ & $\mathrm{H}$ & $\mathrm{M}$ \\
\hline sales & & & $*$ & $*$ & $*$ & $*$ & $\mathrm{H}$ & $\mathrm{M}$ & $\mathrm{M}$ \\
\hline training & & & $*$ & $*$ & $*$ & $*$ & $\mathrm{H}$ & $\mathrm{M}$ & $\mathrm{M}$ \\
\hline medicine & $*$ & $*$ & $*$ & $*$ & $*$ & $*$ & M & $\mathrm{M}$ & M \\
\hline hypermedia & $*$ & $*$ & * & $*$ & $*$ & $*$ & $\mathrm{H}$ & $\mathrm{H}$ & $\mathrm{H}$ \\
\hline \multicolumn{3}{|l|}{ LAN- to - LAN } & \multicolumn{7}{|c|}{ 10-100 Mbit/s } \\
\hline Image & & & \multicolumn{7}{|c|}{$50-5000 \mathrm{kbit} / \mathrm{s}$} \\
\hline file transfer & & & \multicolumn{7}{|c|}{$10-100 \mathrm{Mbit} / \mathrm{s}$} \\
\hline Real time video & & & \multicolumn{7}{|c|}{ 45-150 Mbit/s } \\
\hline
\end{tabular}

The benefits of integration of multimedia service within the communications network are as follows : 1- a single connection, 2- Common management, 3- C0-ordinated dialogues, 4- potentially lower costs. EIII 802.9 ISLAN may represent natural candidate for local access in the short to medium 
term. Other LAN technologies provide with necessary guaranteed BW service would include FDDIII (FDDI adapted for digitized voice and date) [4][9].

\section{Home Working/ Telecommuting Applications}

An increasing trend nowadays and the majority of home workers will require voice, fax and data access to corporate organizations (and vice versa) [1].

Some will also require HD graphics and/or video telephony. The requirement of network home workers into the fabric of corporate organizations will be prevalent in sales, marketing and software development.

Thus, using Public ISDN will enable a more suitable level of service with the corporate network more than dial-up PSTN, and will provide high simultaneous voice and data calls and group TV fax support [12].

\section{Enterprise/ Corporate Network}

These applications will need to run such that unconstrained distribution across the enterprise network is possible [2].

Thus, a requirement for high end-to-end BW, is to ensure short response times with very high bandwidth traffic [2][9]. Hybrid LANs (IEEE 802.9. ISLAN and FDDI-II) will represent excellent candidate in the short to medium term if the real time of the applications is supported (voice, video). In the longer-term ATM over LANs may feature as an ideal local transport technology and also as a compatible technology for linking to future generation, Broadband MANs and WANs[1].

\section{Inter-Enterprise Networks}

An increasing take up of inter-enterprise networking within the many communities of interest. Applications include ordering/ invoicing (traditional EDI), and E-mail through to full electronic business applications for multi-enterprise projects (e.g, aerospace industry) [1].

Requirements Inter-enterprise applications include:1) high availability 2) high BW, 3) open standards plus effective security and 4) network management. Inter-enterprise applications involve the use of a WAN as a "clearing house" typically provided by a third party.

\section{Future Networking Scenarios}

Figure (5) depicts an advanced MAN/WAN high speed network. The primary technologies which are expected to be deployed in this scenario are private Frame Relay between remote major sites, and the early use of SMDS across the mitropolitan area. Both services should operate at data rates of up to $34 \mathrm{Mbit} / \mathrm{s}$. N-ISDN services are forecast to have a respectable penetration in the world by the next following years and therefore are expected to provide a powerful communications platform for smaller sites (or branch offices) and home-workers, providing $2 \mathrm{Mbit} / \mathrm{s}$ primary rate connections to branch offices and $144 \mathrm{Kbit} / \mathrm{s}$ basic rate to the home [9][13]. 

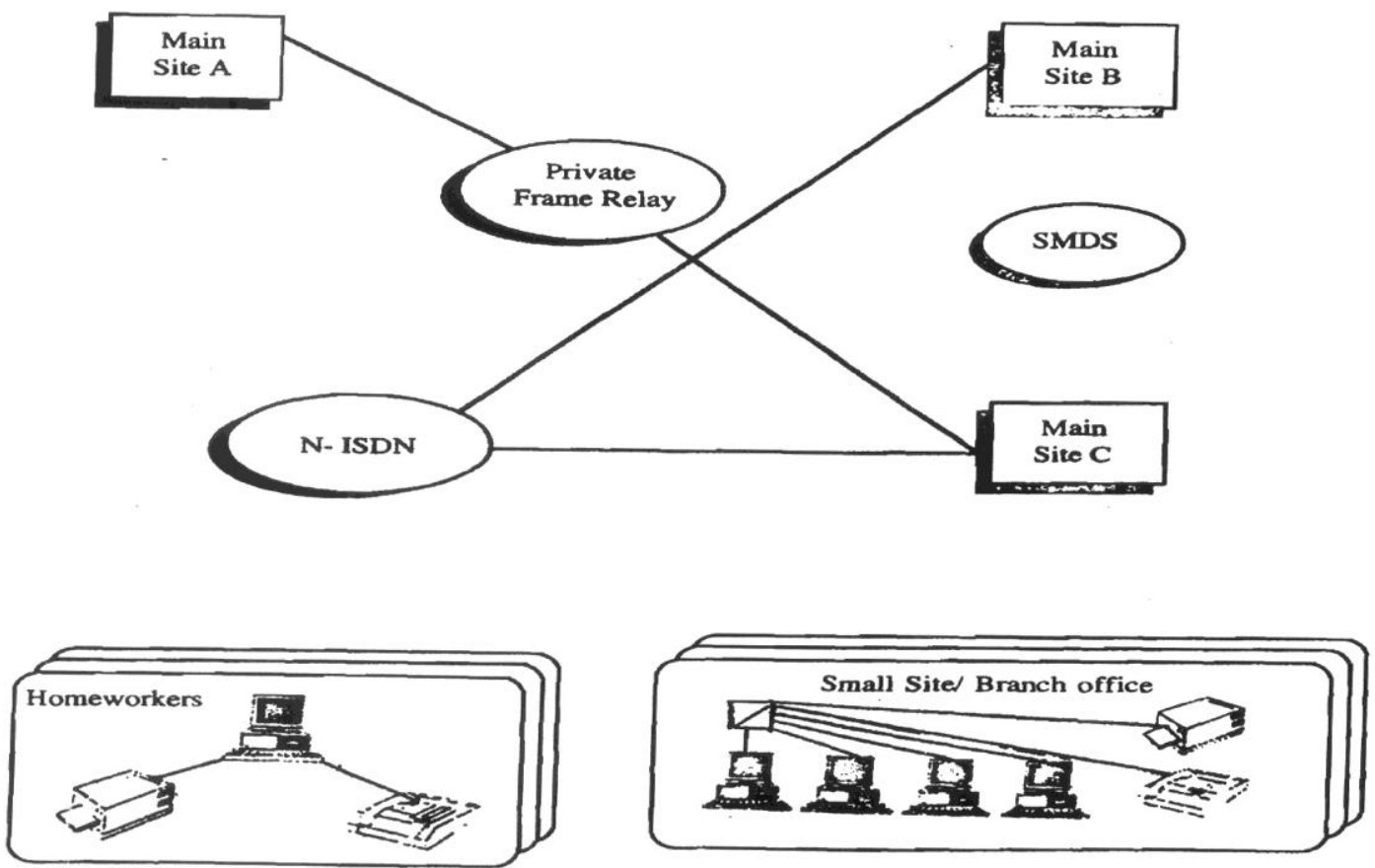

Figure 5: Advanced High Speed Network for 2000[9]

Figure (6) depicts an advanced MAN/WAN high speed network which should be possible in the next few years. The primary technologies which are expected to be deployed in this later scenario are BISDN (ATM) between remote major sites, and the continued use of Switched Multi-megabit Data Service (SMDS).

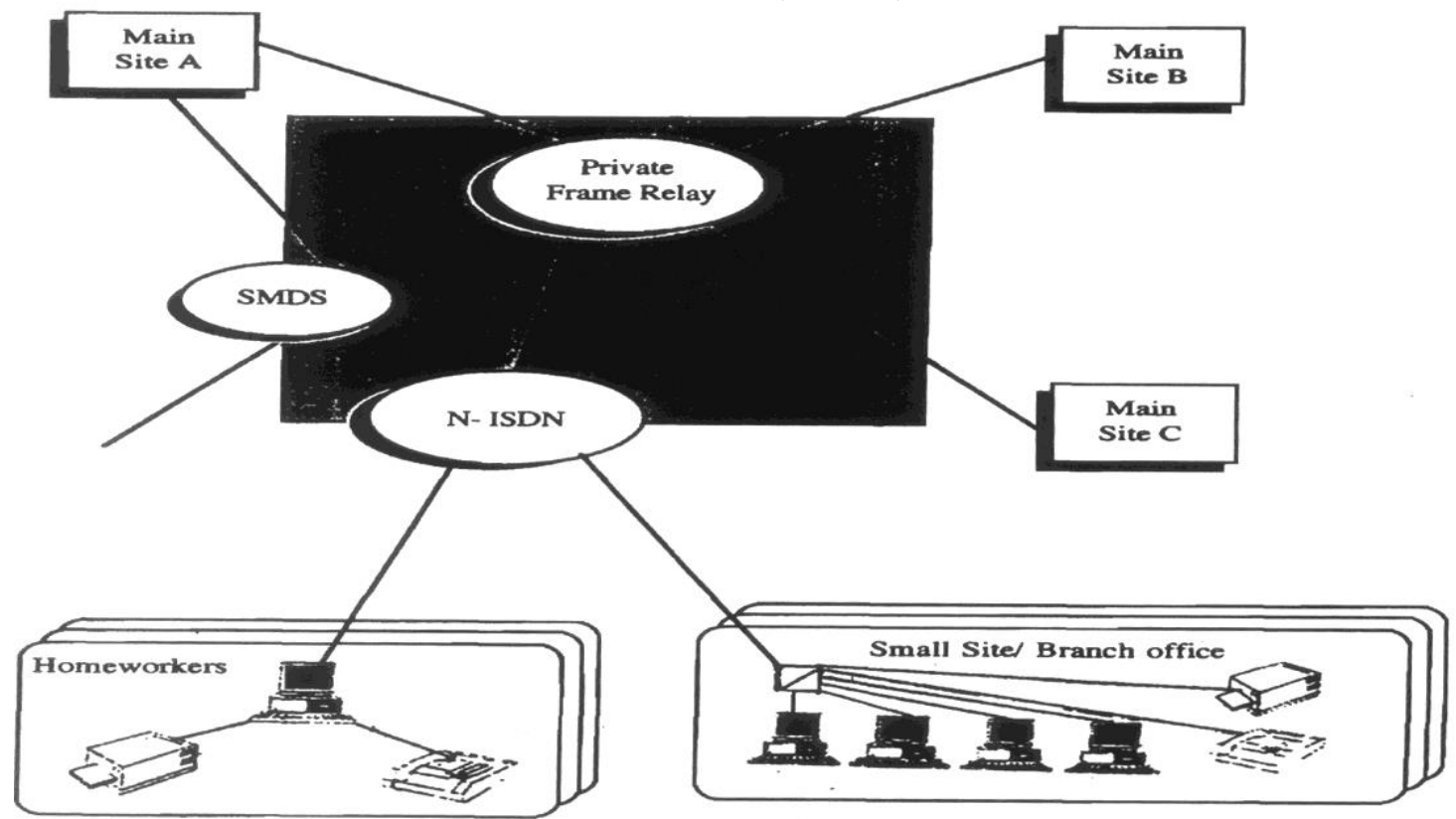

Figure 6: Advanced High Speed Network for 1998[11]

across the metropolitan area. These services should operate over the established SDH transmission network at data rates between $155 \mathrm{Mbit} / \mathrm{s}$ and $622 \mathrm{Mbit} / \mathrm{s}$. N-ISDN services are expected to become ubiquitous by this time, and will continue to provide a powerful communications platform for smaller sites (or branch offices) and home-workers [6][10][13]. 


\section{CONCLUSIONS}

In this paper mentioned to nine factors take increasing exploitation of IS/IT, and have influenced how these new networking technologies will be deployed. An example of the future application was presented.

Many trends will cause a dramatic increase in network bandwidth (BW) requirements over the next years. An example (Image Retrieval) was presented for illustration.

Traffic sizing and forecasting will become more important and the use of traffic analysis tools will become prerequisite in displaying the quality of service statistics and the growth of traffic BW.

The high volume of real time requests across a network will need efficient across methods and high BW to achieve rapid response, initially within a building, then across the wide area as clients and servers become geographically distributed.

Virtual reality is the ultimate application of animated images /graphics, although many of the business uses of this technology have yet to be defined.

An advanced MAN/WAN high-speed network was depicted, which should be presented in the next few years.

The primary technology which are expected to deployed in this later scenario are BOOM (ATM) between remote major sites, and the continued use of SMDS across the metropolitan area.

\section{REFERENCES}

1. Katia Obraczka, S.-H. Li, P.B. Danzig, IEEE Communications, pp 8-22, Sept. (1993).

2. Taranpreet Kaur, et al., ijemr , 2(1), pp. 57-61 (2012).

3. Mario Gerla and R. Pazos-Rangel, IEEE Communications Magazine, 22(2) (2003).

4. F.F. Farahal, M.Sc.thesis submitted, Faculty of engineering, University of Alex. (2014).

5. Stephen M. Alesi, Stanley R. Trollip,"Computer Based Instruction: Methods and development", Prentice-Hall, Inc. Division of Simon and Schuster One Lake Street Upper Saddle River, NJ , United States, October (1984).

6. Misoo Fukuda ,T. Tsuda and et al, IEEE Journal on SACS, 6(3), pp. 476 - 483 (2011).

7. H.P. Yaggioni, IEEE Communications Magazine, 25(11), pp. 20-36 (2007).

8. $\quad$ S.R. Amstutz, IEEE Communications Magazine, 27(9), pp. $50-57$ (2006).

9. Steven E. Minzer, IEEE Communications Magazine, 28(9) ,pp. 17-24 (2001).

10. T.Kamae, IJARCSMS, 24(12), pp. 7-15 (2013).

11. Thomas J. Herr and et al, IEEE Communications Magazine, 24(11), pp. 6-10 (2012).

12. Hitoshi W., IEEE Communications Magazine, 25(12),pp. 74-80 (2004).

13. SEIEI Ohkoshi and et al, IEEE Journal,4(8), pp. 119 